\title{
Infant Mortality Rates for Metro and Nonmetro Counties,* by Race and Hispanic Origin — National Vital Statistics System, United States, 2017
}

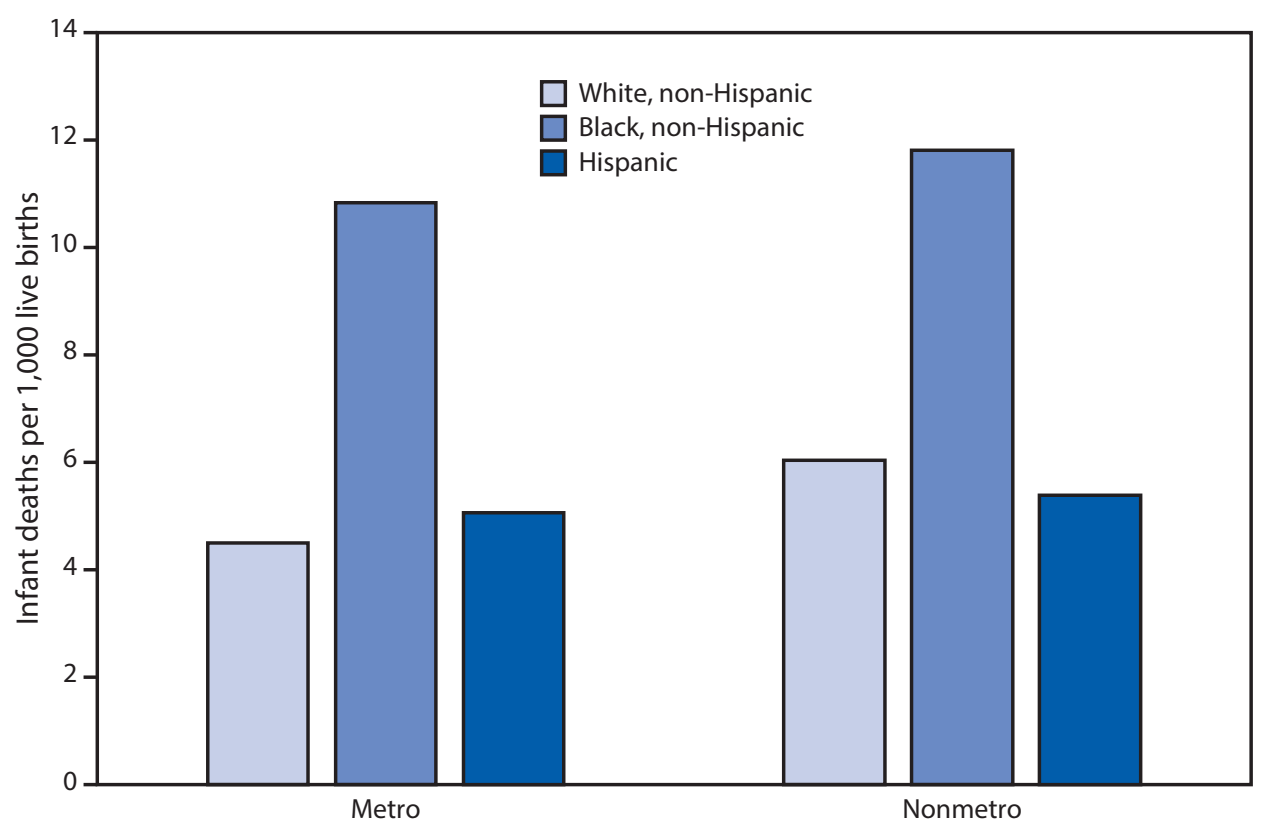

\footnotetext{
* Urbanization level is based on maternal county of residence. Counties were classified according to their metropolitan status using the National Center for Health Statistics Urban-Rural Classification Scheme (https:// www.cdc.gov/nchs/data_access/urban_rural.htm).
}

\begin{abstract}
In metropolitan counties, infant mortality rates were lowest for infants of non-Hispanic white mothers (4.50 infant deaths per 1,000 live births), followed by rates for infants of Hispanic mothers (5.08) and highest for infants of non-Hispanic black mothers (10.84). In nonmetropolitan counties, the mortality rate was lowest for infants of Hispanic mothers (5.38) followed by infants of non-Hispanic white mothers (6.05) and highest for infants of non-Hispanic black mothers (11.81). The infant mortality rate was significantly lower for infants of non-Hispanic white women in metro counties compared with nonmetro counties; differences in rates between metro and nonmetro counties for the two other groups were not significant.
\end{abstract}

Source: National Vital Statistics System, Linked birth/infant death period file, 2017.

Reported by: Danielle M. Ely, PhD, dely@cdc.gov, 301-458-4812. 